\title{
Los Directivos Escolares como Informantes Cualificados de las Políticas Educativas. Sus Opiniones bajo el Gobierno de Michelle Bachelet en Chile (2014-2017)
}

\author{
School Principals as Qualify Informants of Educational Policies. \\ Their Opinions under Michelle Bachelet Chilean Government
} (2014-2017)

\author{
José Weinstein * \\ Gonzalo Muñoz \\ Rosario Rivero
}

Universidad Diego Portales, Chile

\begin{abstract}
Los directivos escolares suelen ser reivindicados en tanto ejecutores de políticas educativas, reconociéndoseles un rol clave para su éxito o fracaso en las escuelas que lideran. Este artículo analiza, a partir de encuestas anuales comparables, la opinión que los directores de centros educativos tuvieron respecto de las políticas educativas desarrolladas en Chile bajo el reformista gobierno de la presidenta Michelle Bachelet (2014-2017). Los resultados dan cuenta que la iniciativa que más marcó la opinión de los directivos fue la ley de inclusión educativa, aprobada de manera controversial a inicios del período. En torno a ella se produjo un mayor pesimismo inicial respecto del futuro de la educación nacional, así como se tendió a distanciar la opinión de los directivos que trabajan en el sector público respecto del privado. Igualmente puede apreciarse que la opinión de los directivos es dinámica, modificándose en el transcurso del gobierno, que aquella suele manifestar la urgencia de ciertas políticas educativas (como la mejora de la formación inicial docente) por sobre el resto y que también brinda valiosa información sobre los efectos de las políticas en los centros educativos mismos. Por ello, dada su calidad de informantes cualificados, los tomadores de decisión debiesen considerar sistemáticamente sus opiniones en el diseño e implementación de las políticas.
\end{abstract}

Descriptores: Liderazgo; Gestión de la educación; Política educacional; Gobierno.

School managers are often vindicated as executors of educational policies, recognizing a key role for their success or failure in the schools they lead. This article analyzes, from comparable annual surveys, the opinion that the directors of educational centers had regarding the educational policies developed in Chile under the reformist government of President Michelle Bachelet (2014-2017). The results show that the initiative that most marked the opinion of the directors was the law of educational inclusion, approved controversially at the beginning of the period. Around it there was greater initial pessimism regarding the future of national education, as well as a tendency to distance the opinion of managers working in the public sector with respect to the private sector. It can also be seen that the opinion of managers is dynamic, changing in the course of the government, which usually manifests the urgency of certain educational policies (such as improving initial teacher training) above the rest and also provides valuable information on the effects of policies in the educational centers themselves. Therefore, given their quality as qualified informants, decision makers should systematically consider their opinions in the design and implementation of policies.

Keywords: Leadership; Educational management; Educational policy; Government.

*Contacto: jose.weinstein@gmail.com

ISSN: $1696-4713$

www.rinace.net/reice/

revistas.uam.es/reice
Recibido: $\quad 2$ de abril 2018

$1^{\text {a }}$ Evaluación: 13 de abril 2018

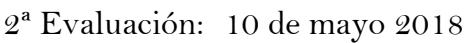

Aceptado: $\quad 26$ de mayo 2018 


\section{Introducción}

Los directivos escolares suelen ser reivindicados en tanto ejecutores de políticas educativas, atribuyéndoseles un rol decisivo para el éxito (o fracaso) de dichas iniciativas en las escuelas que conducen (Fullan, 2002, 2017). Su demostrada incidencia en la mejora escolar, apoyada por la constatación recurrente de ser el segundo factor intra-escuela más significativo (Barber y Mourshed, 2007; Leithwood, Harris y Hopkins, 2008) y su reconocido papel transformador de las prácticas individuales y colectivas de los docentes (Day, Gu y Sammons, 2016; Seashore-Louis, Dretzke y Wahlstrom, 2010), les ha ubicado como actores indispensables para el cambio educativo. Sin ellos, se ha afirmado, las reformas a gran escala no son posibles (Hargreaves y Fullan, 2012).

Por otra parte, la evidencia internacional es convergente en que la buena implementación es uno de los principales desafíos de las políticas y esfuerzos de reforma educacional (Fixsen et al., 2005) y en que los propósitos de dichas políticas difícilmente terminan cumpliéndose tal como se esperaba a nivel de las unidades educativas (Rigby, Woulfin y März, 2016; Stein, Grover y Henningsen, 1996). Además, la literatura también releva que durante los procesos de reforma educativa suele existir una tensión entre los niveles macro institucionales y las creencias y motivaciones de los actores a nivel de las escuelas (Elmore y Mc-Laughlin, 1982; Fullan, 1985; Rigby, Woulfin y März, 2016), y que los líderes escolares tienen un rol fundamental en la interpretación, adecuación y apropiación de las políticas (O'Laughlin y Lindle, 2015; Sun et al., 2013; Wholstetter et al., 2015). En Chile y América Latina estos ámbitos se han investigado escasamente y, por ende, poco se sabe sobre cómo los directivos perciben y experimentan las políticas que están llamados a materializar.

Durante los cuatro años (2014-2017) del gobierno de la Presidenta Michelle Bachelet en Chile se iniciaron importantes procesos de reforma. Así, se aprobaron tres leyes trascendentes: la ley de inclusión, que introduce un nuevo marco normativo para el sector privado subvencionado; la ley de carrera docente, que fija nuevas condiciones y una trayectoria profesional para los docentes de aula; y la ley de educación pública, que transfiere la gestión de los establecimientos públicos desde los municipios hacia nuevos servicios locales de educación. Adicionalmente, se continuaron implementando políticas educativas que provenían de gobiernos anteriores y que, en algunos casos, alcanzaron su materialización plena (como el denominado "sistema de aseguramiento de la calidad" 1 ). El rol y las atribuciones de los directores de centros educativos no se vio modificado en lo sustancial, aunque la gestión de las nuevas políticas sí introdujo algunas nuevas obligaciones para los directivos, como la responsabilidad de elaborar planes de mejoramiento educativo o la de establecer un itinerario de desarrollo profesional para los docentes de su escuela.

En el presente artículo se realiza un análisis de las opiniones de los directivos escolares respecto de las políticas educativas de este reformista gobierno. Más específicamente, se brinda evidencia respecto de la evaluación que ellos realizan respecto de: la calidad y equidad educativa en general; el desempeño sectorial del gobierno; las principales políticas

\footnotetext{
${ }^{1}$ Este sistema fue aprobado por ley el año 2011 y consiste en la conformación de una nueva institucionalidad educacional (se crea una Superintendencia de Educación y una Agencia de Calidad, que complementan la tarea del Ministerio de Educación) y de un conjunto de herramientas de política (como los estándares de aprendizaje y su evaluación permanente) con las cuales se espera mejorar la calidad de la educación escolar.
} 
impulsadas y sus efectos; y las políticas educativas que creen que debieran priorizarse en adelante. Para este análisis, se emplea una fuente de información escasamente disponible en el concierto internacional: una encuesta de opinión anual, desarrollada en estos cuatro años por parte de los autores, denominada "La voz de los directores". En esta encuesta se reitera sistemáticamente ciertos temas (y preguntas), de manera que puede conocerse la evolución de las opiniones en el período. Igualmente, ellas permiten distinguir subgrupos de directores en torno a algunas variables relevantes, en particular la referida a si se desempeñan en centros públicos o privados, de manera de indagar en las diferencias que atraviesan a este trascendental actor educativo.

El presente artículo parte por describir el contexto de políticas educativas del gobierno de Michelle Bachelet, luego se detiene en las características de la encuesta realizada, seguido de una sistematización de los principales resultados encontrados, para finalizar con ciertas conclusiones y discusiones.

\section{El contexto: La reforma educacional del período 2014-2017 en Chile}

Chile ha logrado dar pasos sustantivos en las últimas décadas en materia de cobertura de su educación obligatoria (entre los 5 y 18 años), así como también en la generación de ciertas condiciones de base para el buen funcionamiento del sistema educativo (OECD, 2017; Rivas, 2015; Weinstein y Muñoz, 2009). Sin embargo, en materia de aprendizajes y siguiendo la información que proveen las pruebas estandarizadas internacionales (PISA, TIMSS y TERCE) y nacionales (SIMCE), se ha podido constatar que, si bien Chile posee una situación favorable comparada en el contexto de América Latina y se han producido avances específicos en las últimas décadas en áreas como Lectura y Ciencia, siguen existiendo graves carencias (OECD, 2017). Esta situación de resultados mixtos (alta cobertura con rezagos en calidad de aprendizajes) convive con evidencia contundente respecto a la alta segregación del sistema escolar chileno y la persistente falta de equidad en la distribución de oportunidades de aprendizaje entre grupos socioeconómicos. La desigualdad y segregación no sólo es comparativamente alta, sino que ha ido en aumento en los últimos años (Bellei, 2016).

Si bien los fundamentos organizativos del sistema escolar chileno se remontan al siglo XIX (Serrano, 2012), parte importante de su marco de funcionamiento fue modificado sustantivamente a través de las políticas de descentralización y privatización puestas en práctica en la década del 80 por la dictadura militar del General Pinochet (1973-1990). Esta dictadura traspasó la educación pública a los municipios, creó un sistema de financiamiento mediante subsidios y utilizó incentivos legales y de mercado para estimular la proliferación de establecimientos privados financiados por el estado (Cox, 2012). Sobre esta base, los gobiernos democráticos de los años 90 en Chile desarrollaron políticas que se focalizaron en mejorar la inversión y las condiciones en las que se desarrollaba el proceso educativo para potenciar su calidad y equidad, sin lograr modificar los componentes institucionales y de financiamiento que se habían originado a comienzos de la década del 80.

De este modo, se configuró un sistema educativo mixto, y con características únicas en el concierto internacional, básicamente por sus niveles de privatización y competencia, entendidos -al menos en su génesis dictatorial- como dinamizadores de la calidad 
educativa (Bellei, Cabalín y Orellana, 2014). El resultado de esta base institucional (constituida entre 1973 y 1990) y sus modificaciones (realizadas en el período entre 1990 y 2013) no alcanzó todo el éxito esperado en calidad y equidad educativa (Muñoz, 2013), aunque sí amplió fuertemente las expectativas educativas de distintos grupos sociales, en particular de las clases medias emergentes (Weinstein y Muñoz, 2009). Esto se ha traducido en movimientos sociales ${ }^{2}$ que han demandado reformas estructurales a la educación y que han incidido directamente en la agenda del sector.

En este escenario, Chile desde el año 2014 inició un proceso de reforma a su sistema escolar, que fue posible gracias a una combinación de factores sociales y políticos (Muñoz y Weinstein, en prensa). Así, en su segundo período de gobierno, la presidenta Bachelet asumió el compromiso por un conjunto de cambios significativos en la estructura del sistema escolar, cuyo eje discursivo central fue el del "derecho a la educación" explicitando además el objetivo de reducir y limitar la mercantilización del proceso educacional (Programa de Gobierno Bachelet, 2014).

Para ello, en primer lugar, el gobierno propuso legislar y aprobó lo que se conoce como la "ley de inclusión". Esta ley, por una parte, pone fin al lucro en la educación escolar financiada por el Estado, asegurando así que los recursos de la subvención se destinen íntegramente a mejorar la calidad de la educación. Por otra, ella elimina gradualmente las barreras de acceso al sistema escolar, descartando todo tipo de selección académica y financiera de los estudiantes, garantizando así el ejercicio de la libertad de elección por parte de las familias y promoviendo un mayor grado de mixtura social al interior de las escuelas. Para lograr este objetivo, la ley definió una trayectoria gradual a través de la cual las escuelas privadas subvencionadas se transformarán completamente en instituciones sin fines de lucro, e irán pasando a un régimen de total gratuidad para las familias (a través de un aumento de las subvenciones provistas por el estado). Asimismo, se comenzó a implementar desde el año 2016 un sistema de admisión aleatorio de estudiantes que ya ha sido implementado en 5 regiones del país.

En segundo lugar, el gobierno de Bachelet instaló una nueva carrera docente, que mejora las condiciones laborales del profesorado y apunta a fortalecer las capacidades del sistema escolar. Esta política, que cubre a todos los docentes del sistema público y privado financiado por el Estado, aumenta las exigencias para los estudiantes de pedagogía y sus formadores, establece la inducción como un proceso formal en la incorporación de los nuevos profesores al sistema, crea un sistema de reconocimiento profesional que incentiva económicamente el avance en el desempeño e identifica las fortalezas y debilidades de los docentes para orientar su formación, mejora sustantivamente las remuneraciones de base de los profesionales de la educación (30\% en promedio), y aumenta las horas no lectivas de los docentes a un 35\% (anteriormente sólo alcanzaba un 25\%), entre varias otras medidas. El año 2017 comenzó la implementación de esta reforma, principalmente a través de la mejora en las condiciones laborales de los profesores y profesoras del sector público.

Por último, hacia el final del año 2017 se aprobó también la ley que crea un Nuevo Sistema de Educación Pública, traspasando la responsabilidad de su administración y gestión desde

\footnotetext{
${ }^{2}$ Chile ha vivido en las últimas dos décadas dos expresiones fuertes de movilización social y estudiantil, que han demandado transformaciones al sistema educativo. La primera de ellas fue liderada por los estudiantes secundarios (año 2006), mientras que la segunda por el movimiento universitario (año 2011). Ambos movimientos tuvieron un importante apoyo ciudadano y efectos relevantes en la agenda de políticas educacionales de los últimos años (Muñoz, 2013; UNICEF, 2014).
} 
los actuales municipios a una institucionalidad nueva: los Servicios Locales de Educación, que cuentan con nuevas capacidades para gestionar los más de 5.000 establecimientos públicos. Estos servicios - de giro único y dirigidos por profesionales elegidos por un sistema de alta dirección pública- contarán con financiamiento basal, con equipos especializados para apoyar técnicamente a las unidades educativas y con la asesoría permanente de un Consejo Local. Debido a la complejidad de este proyecto, su implementación considera también un proceso gradual, en este caso de 8 años.

Estas tres reformas supusieron un enorme esfuerzo financiero del estado chileno, que se abordó a través de una reforma tributaria que permitirá en régimen recaudar recursos cercanos a los 6 mil millones de dólares, de los cuales aproximadamente dos tercios fueron destinados a los cambios en la educación escolar. El cuadro 1 resume los aspectos clave de cada una de las reformas impulsadas, así como los momentos clave de su tramitación e implementación.

Las tres leyes aprobadas enfrentaron una tramitación difícil y conflictiva. La mayoría de las organizaciones de actores implicados en los cambios (sostenedores, docentes y padres de familia, principalmente) mantuvieron una posición de resistencia, lo que sumado a una débil gestión política del gobierno hizo que durante el ciclo 2014-2017 la reforma impulsada fuera quedándose sin una base mayoritaria de apoyo político y social (CEP, 2015). Las tres leyes encontraron oposición en grupos de interés específicos: así, si la ley de inclusión se confrontó con los sostenedores/dueños de los establecimientos privados subvencionados, la ley de nueva carrera tuvo también la resistencia del gremio docente y la ley de nueva educación pública la de una parte importante alcaldes que se negaban a desprenderse de las escuelas. Los medios de comunicación de mayor relevancia jugaron un rol fundamental (sobre todo durante la tramitación de la ley de inclusión) en acrecentar la sensación de amenaza o posibles problemas asociados a cada uno de estos cambios y en privilegiar la confrontación entre actores por sobre la entrega de información de calidad sobre las leyes y sus consecuencias (Cabalín y Antezana, 2016). Miradas en una perspectiva de futuro, estas reformas enfrentarán su principal desafío en su capacidad para incidir efectivamente en el sistema escolar y sus principales actores, traduciendo estas nuevas condiciones y estos mayores recursos en mejoramiento de los procesos y resultados educacionales en las aulas y los centros educativos. Por esta misma razón es que se vuelve relevante observar cómo los directores de centros educativos han percibido y experimentado estos cambios.

\section{Método}

Este artículo se basa en un estudio de carácter cuantitativo, reportando resultados descriptivos en base a la aplicación de una encuesta "La voz de los Directores", aplicada anualmente desde el año 2013 y de cobertura nacional, cuya población objetivo son todos los directores y directoras del país. 
Cuadro 1. Reformas Educativas del Gobierno Bachelet (2014-2017)

\begin{tabular}{|c|c|c|c|c|}
\hline REFORMA & OBJETIVO & MEDIDAS CLAVE & $\begin{array}{l}\text { PERÍODO DE } \\
\text { TRAMITACIÓN } \\
\text { DE LA LEY }\end{array}$ & $\begin{array}{c}\text { PERÍODO DE } \\
\text { IMPLEMENTACIÓN DE } \\
\text { LA LEY }\end{array}$ \\
\hline $\begin{array}{l}\text { Ley de } \\
\text { Inclusión }\end{array}$ & $\begin{array}{l}\text { Garantizar que todo el sistema } \\
\text { financiado por el Estado se } \\
\text { enmarque en un régimen } \\
\text { público, inclusivo y gratuito. }\end{array}$ & $\begin{array}{l}\text { Fin del lucro en la educación privada subvencionada } \\
\text { Fin del financiamiento compartido en la educación privada } \\
\text { subvencionada (gratuidad total) } \\
\text { Fin de los procesos de selección en toda la educación financiada por el } \\
\text { Estado. Creación de un sistema aleatorio de admisión } \\
\text { Regulación de los procesos de expulsión en toda la educación } \\
\text { financiada por el Estado }\end{array}$ & $\begin{array}{l}\text { Mayo } 2014 \\
\quad- \\
\text { Enero } 2015\end{array}$ & $\begin{array}{l}\text { Desde el año } 2016 \text { (en } \\
\text { régimen total cerca } \\
\text { del 2025) }\end{array}$ \\
\hline $\begin{array}{l}\text { Carrera } \\
\text { Docente }\end{array}$ & $\begin{array}{l}\text { Mejorar las condiciones } \\
\text { laborales de los docentes del } \\
\text { sistema financiado por el } \\
\text { Estado y establecer una } \\
\text { carrera atractiva para la } \\
\text { profesión docente }\end{array}$ & $\begin{array}{l}\text { Aumento de las remuneraciones de los docentes del sector público y } \\
\text { privado subvencionado ( } 30 \% \text { en promedio) } \\
\text { Aumento de horas no lectivas (de un } 25 \% \text { a } 35 \text { o } 40 \% \text { dependiendo del } \\
\text { tipo de centro) } \\
\text { Establecimiento de una carrera que distingue tramos (en base a la } \\
\text { experiencia y una evaluación de desempeño) y asocia a ellos las } \\
\text { remuneraciones } \\
\text { Mayores exigencias para el ingreso a carreras de pedagogía }\end{array}$ & $\begin{array}{l}\text { Marzo } 2015 \\
\quad- \\
\text { Enero } 2016\end{array}$ & $\begin{array}{l}\text { Desde el año } 2017 \text { (en } \\
\text { régimen total el } \\
2025)\end{array}$ \\
\hline $\begin{array}{l}\text { Nueva } \\
\text { Educación } \\
\text { Pública }\end{array}$ & $\begin{array}{l}\text { Poner en marcha una nueva } \\
\text { institucionalidad a cargo de } \\
\text { las escuelas públicas, ahora } \\
\text { fuera del sistema municipal }\end{array}$ & $\begin{array}{l}\text { Establece el traspaso gradual de todos los centros públicos desde los } \\
\text { municipios a los nuevos Servicios Locales de Educación, que tienen } \\
\text { por función única la administración educacional } \\
\text { Se crea una institucionalidad nacional (Dirección de Educación } \\
\text { Pública), que acompaña a los Servicios Locales } \\
\text { Se pone en marcha un sistema de accountability local para la educación } \\
\text { pública, a través de la creación de Consejos Directivos y Consejos } \\
\text { Locales }\end{array}$ & $\begin{array}{l}\text { Noviembre } \\
2015 \\
- \\
\text { Noviembre } \\
2017\end{array}$ & $\begin{array}{l}\text { Desde el año } 2018 \text { (en } \\
\text { régimen total el } \\
2025)\end{array}$ \\
\hline
\end{tabular}


La encuesta "La voz de los directores" es un instrumento que consta de dos secciones. Una primera sección, utilizada en este estudio, que contiene 7 preguntas cerradas que abordan la percepción de los directores sobre la calidad de la educación en general y sobre algunas políticas educativas recientes. Estas preguntas son fijas, repitiéndose durante las distintas aplicaciones. La segunda sección del instrumento varía de año en año, cambiando el número de preguntas y las temáticas que abordan, incorporándose nuevas preguntas sobre nuevas iniciativas gubernamentales. En sus cinco años de aplicación, esta última sección ha contenido entre 20 y 30 preguntas cerradas y ha abordado temáticas como formación y experiencia de los directores, conocimiento para ejercer un liderazgo efectivo y evaluación de los directores sobre las políticas de liderazgo implementadas, entre otras. En el año 2017 se incluyeron 3 ítems que abordan la percepción de los directores sobre las principales políticas educativas implementadas en el gobierno de Bachelet. Este instrumento ha sido anualmente debidamente testeado entre directivos en términos de su comprensión, tiempo de aplicación y validez.

La aplicación de la encuesta se realiza en períodos fijos de tiempo, de no más de tres meses, en el segundo semestre del año y ha estado a cargo de instituciones especializadas. La aplicación del cuestionario se realiza mediante un formato auto-aplicado y on line. El cuestionario es enviado por correo electrónico al universo de directores, de enseñanza básica y media, que poseen una dirección válida. Luego se reenvía electrónicamente la encuesta buscando ampliar la tasa de respuesta lograda inicialmente. Finalmente se procede a llamar telefónicamente a establecimientos insistiendo en la invitación al director a completar la encuesta y enviarla. En este paso final se procede mediante un muestreo aleatorio por cuotas, priorizando a determinados grupos de establecimientos para lograr una muestra proporcional a la distribución del universo de establecimientos según su dependencia administrativa.

El tamaño de la muestra parte de un número mínimo de encuestados que deben responder y que, en función del universo de 9 mil directores, es de 520 casos. Por ello, como muestra el cuadro 2, la muestra ha variado entre un mínimo de 523 encuestados (2014) y un máximo de 627 (2017). Se busca que la muestra se corresponda con la distribución del universo de directores en ciertas variables claves (como la dependencia pública y privada) de manera de aumentar su representatividad. Para todos los años de aplicación, el error muestral puede estimarse, bajo el supuesto de que no hay diferencias significativas entre las características de la muestra y del universo, en $4 \%$ con un $95 \%$ de confianza.

Cuadro 2. Tamaño de la muestra según año de aplicación

\begin{tabular}{lc}
\hline Ã̃o & MUESTRA \\
\hline 2013 & 582 \\
2014 & 523 \\
2015 & 542 \\
2016 & 575 \\
2017 & 627 \\
\hline
\end{tabular}

Fuente: Elaboración propia.

Posteriormente se procede a realizar un análisis estadístico descriptivo de los datos. Se analizan la proporción de directores según su grado deacuerdo/desacuerdo en los ítems consultados, como también el promedio de notas que los directores asignan al desempeño del gobierno en los últimos años. Aparte de las comparaciones de las respuestas generales de los encuestados en el tiempo, se procede al análisis de las diferencias existentes en base 
a la dependencia administrativa de los establecimientos en que los directivos trabajan o bien de sus propias características personales. Para la comparación de medias se realiza un test $\mathrm{t}$ y para la comparación de proporciones se realiza test $\mathrm{z}$. A su vez, se analizan las tendencias de las respuestas de los directores para aquellos ítems que han sido consultados al menos 3 años. Todos los análisis presentados fueron realizados utilizando el paquete estadístico Spss.

\section{Resultados}

Las opiniones de los directores recogidas por la encuesta pueden ser agrupadas en cuatro temas mayores: la visión general de la calidad de la educación chilena; la opinión general sobre la acción del gobierno en materia educacional; la evaluación de las principales políticas específicas que el gobierno ha impulsado; y las prioridades de política educativa que consideran que debiesen ser impulsadas.

\subsection{Visión general de la calidad de la educación chilena}

Los directivos tienen una opinión muy mayoritaria de que la educación chilena es mediocre en términos de su calidad. En una escala de 1 a 7 , la nota promedio que recibe es apenas superior al $4 .{ }^{3}$ Esta calificación general tiene variaciones muy menores durante los cuatro años de Michelle Bachelet y era también semejante el año inmediatamente anterior a que se iniciara su gobierno, como muestra en gráfico 1.

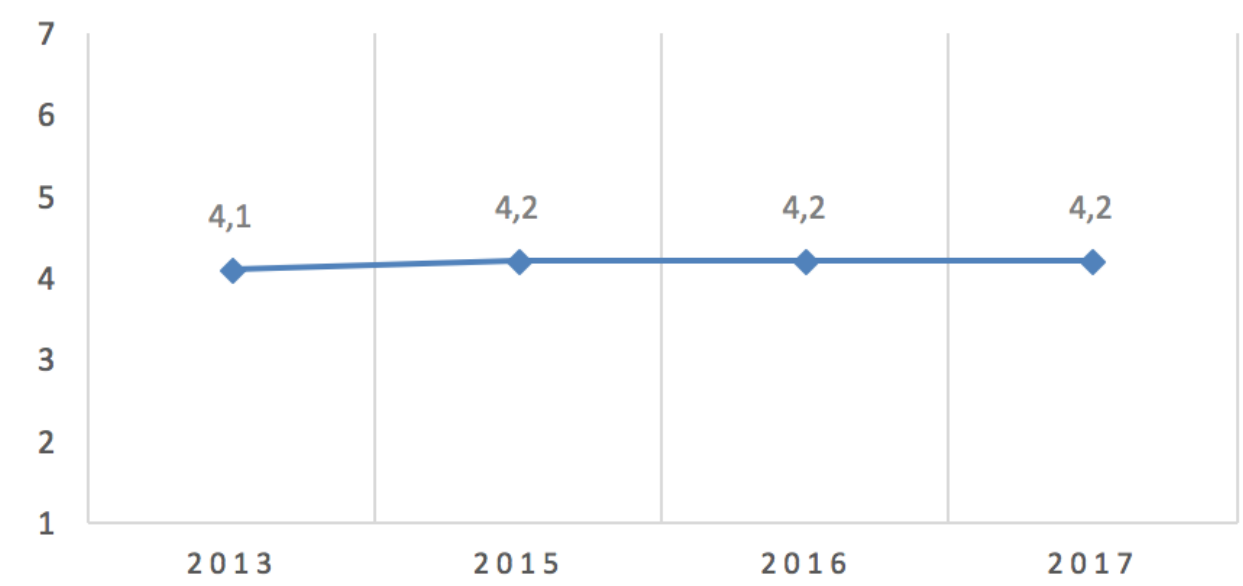

Gráfico 1. ¿Qué nota de 1 a 7, donde 1 es pésimo y 7 es excelente, le pondría a la calidad de educación en Chile?

Fuente: Encuesta "La Voz de los Directores".

La principal diferencia observada en esta opinión general refiere a la dependencia en que trabajan los directivos, dándose una tendencia que se repetirá frente a otras temáticas: los directores del sector público tienden a ser más apreciativos de la calidad de la educación chilena que aquellos, más críticos, del sector privado.

\footnotetext{
${ }^{3}$ En Chile se acostumbra usar la escala de notas de uno a siete, y el cuatro es habitualmente la nota mínima de aprobación. De hecho, con menos de cuatro se suele hablar de "notas rojas" puesto que impiden la aprobación de una asignatura o la promoción escolar, mientras que del cuatro hacia arriba se tienen "notas azules".
} 
Se constata una significativa distancia entre la opinión directiva de la educación chilena en general respecto de la que los directivos poseen sobre el establecimiento que dirigen. De hecho, los encuestados ponen, en promedio, un punto más (sobre siete) cuando de opinar de la calidad educativa de su propio establecimiento se trata. De manera de que si construyéramos la apreciación sobre la calidad del sistema en base a la agregación estadística de la percepción de lo que ocurre en cada uno de los colegios tendríamos una opinión directiva que daría cuenta de una educación chilena moderadamente buena (iy ya no mediocre!). La distancia entre el juicio general y el juicio específico se hace más aguda siguiendo la dependencia: los privados pagados son así los más críticos de la educación chilena en general, pero los más valorizadores de la calidad del establecimiento que lideran, mientras que lo contrario acontece con los directivos del sector público.

Se consultó a los directivos respecto de su visión de la actual calidad educativa en relación con cinco años atrás, de manera de intentar visualizar cuál era su percepción temporal de avance, estancamiento o retroceso. Hacia el término del gobierno, la tendencia es que el mayor porcentaje se ubica entre quienes consideran que no existen mayores variaciones durante el lustro, existiendo un grupo significativo que sí aprecia cambios positivos y un grupo más pequeño (pero no despreciable) que los ve en la dirección opuesta. En este enjuiciamiento temporal se puede apreciar con mayor nitidez la diferencia existente entre los directivos de acuerdo a si trabajan en establecimientos públicos o privados, como puede notarse en el cuadro 3.

Cuadro 3. Comparación de la educación actual respecto a 5 años atrás

\begin{tabular}{lrccc}
\hline & Total & MUNiCIPAL & $\begin{array}{c}\text { PARTICUlaR } \\
\text { SUBVENCIONADO }\end{array}$ & $\begin{array}{c}\text { PARTICULAR } \\
\text { PAGADO }\end{array}$ \\
\hline $\begin{array}{l}\text { Ha empeorado } \\
\text { No ha mejorado } \\
\text { ni empeorado }\end{array}$ & $24 \%$ & $20 \%$ & $27 \%$ & $35 \%$ \\
Ha mejorado & $41 \%$ & $38 \%$ & $45 \%$ & $44 \%$ \\
\hline Total & $35 \%$ & $42 \% *$ & $28 \%$ & $21 \%$ \\
\hline
\end{tabular}

Nota: Base Encuesta 2017. Total directores $\mathrm{N}=627$. * Las diferencias entre los porcentajes correspondientes a cada dependencia administrativa, respecto de las otras dos categorías, son estadísticamente significativas con un 95\% de confianza.

Fuente: Elaboración propia.

La opinión sobre el pasado se complementó con una sobre el futuro, consultándoles a los directores sobre cómo visualizan a la educación chilena en cinco años más. Este juicio da cuenta del optimismo (o pesimismo) que se tiene hoy sobre el devenir del sector educacional y encierra también una visión del presente. En este caso, la opinión mayoritaria es la de estabilidad y no de mayor cambio, con un grupo significativo "optimista" que sí cree que habrá un mejoramiento y un grupo más pequeño "pesimista" que piensa que se empeorará. Se repite la visión diferenciada según dependencia, como puede apreciarse en el cuadro siguiente con los resultados de la encuesta 2017 (cuadro 4).

La lectura comparada de las encuestas y su evolución durante los años del gobierno de Bachelet da cuenta de una modificación parcial, pero significativa, de la opinión directiva sobre la realidad educacional. En efecto, si bien el juicio genérico sobre la calidad educativa se mantiene estable en los cuatro años, no ocurre lo mismo respecto de la visión del pasado y sobretodo del futuro. La tendencia es que en el primer año de gobierno se produce una 
situación de desaliento y de mayor criticidad, la que se va revirtiendo gradualmente, de manera que en el año final del mandato aumenta la percepción positiva (gráfico 2).

Cuadro 4. Evolución de la educación en los próximos 5 años

\begin{tabular}{lcccc}
\hline & Total & MUNICIPAL & $\begin{array}{c}\text { PARTICULAR } \\
\text { SUBVENCIONADO }\end{array}$ & $\begin{array}{c}\text { PARTICULAR } \\
\text { PAGADO }\end{array}$ \\
\hline $\begin{array}{l}\text { Peor } \\
\text { Igual o bastante }\end{array}$ & $10 \%$ & $8 \%$ & $13 \%$ & $6 \%$ \\
$\begin{array}{l}\text { similar } \\
\text { Mejor }\end{array}$ & $55 \%$ & $50 \% *$ & $61 \% *$ & $59 \%$ \\
\hline Total & $35 \%$ & $42 \% *$ & $26 \% *$ & $35 \% *$ \\
\hline
\end{tabular}

Nota: Base Encuesta 2017. Total directores $\mathrm{N}=627$. *Las diferencias entre los porcentajes correspondientes a cada dependencia administrativa, respecto de las otras dos categorías, son estadísticamente significativas con un 95\% de confianza.

Fuente: Elaboración propia.

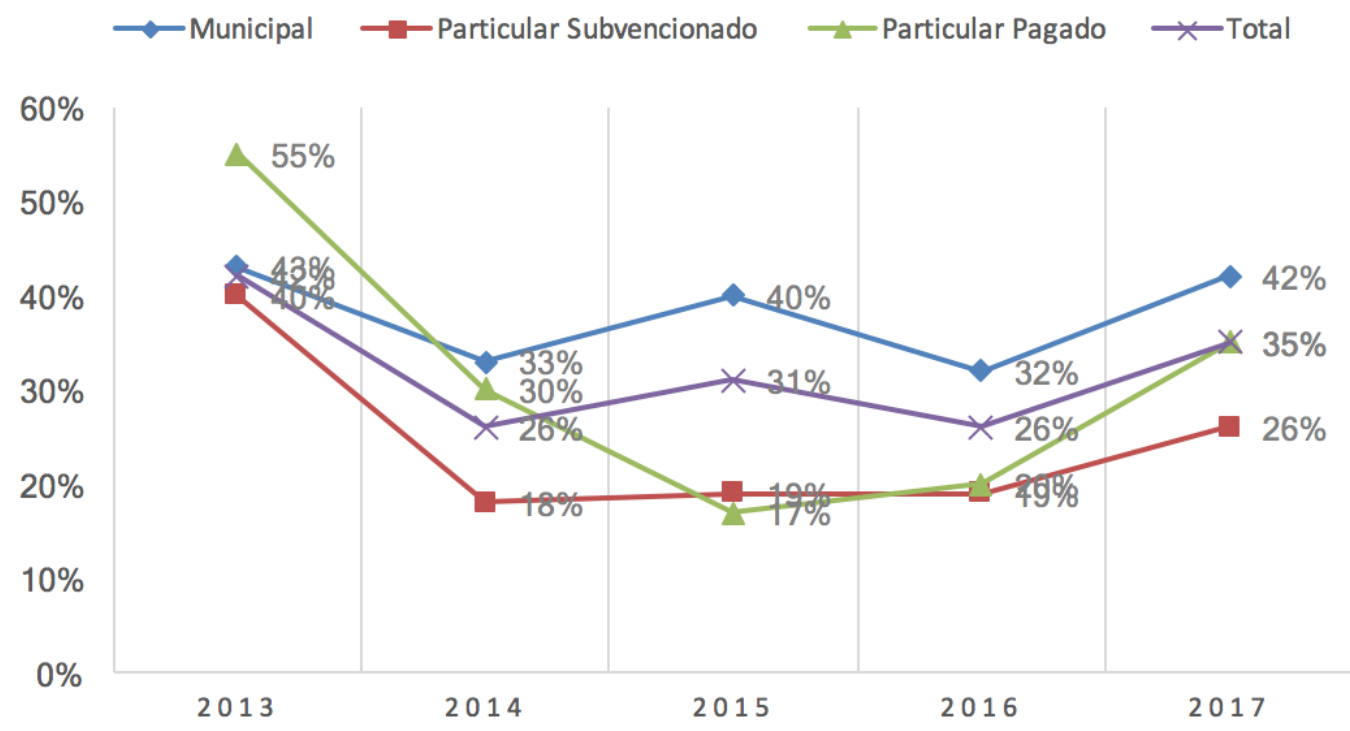

Gráfico 2. A su juicio, ¿Cómo cree que será la educación en 5 años más? (\%Mejor)

Fuente: Encuesta "La Voz de los Directores".

Dicho en guarismos: si quienes veían un mejor futuro para la educación alcanzaban, en promedio, un $28 \%$ entre el 2014 y el 2016, para el 2017 ellos llegan al 35\%, mientras que quienes creían que el futuro educativo sería peor alcanzaban al 23\% el 2014 y se habían reducido tres años después a solamente el $10 \%$. Así como hay que relevar esta gradual "tendencia al alza" en la subjetividad directiva, es también necesario remarcar la existencia, durante el primer año de gobierno, de un shock inicial. En efecto, la comparación con los datos de la encuesta del año 2013 (pre-Bachelet) demuestran una caída drástica en cuanto a la visión del futuro educativo: nada menos que el $42 \%$ de los directores estaba entonces optimista respecto de cómo sería la educación chilena dentro de un quinquenio. Como se verá más adelante, esta brusca declinación pareciera deberse principalmente al proceso de discusión de la ley de inclusión y a su recepción inicialmente negativa por parte principalmente del sector privado, que se sintió afectado directamente por las nuevas "reglas del juego" de esta legislación. 


\subsection{Opinión sobre el desempeño del gobierno}

Los directivos encuestados tienen una opinión crítica del desempeño del gobierno en materias de calidad y equidad educativa. En efecto, al solicitarles que pusieran una nota al gobierno en términos del mejoramiento de estos aspectos claves del sistema escolar, el promedio se ubicó cercano al cuatro (en una escala de 1 a 7). Desde el año 2015 la encuesta dividió en dos esta consulta, lo que permitió detectar que existía una diferencia de opinión en cuanto a ambas dimensiones, siendo la labor gubernamental de mejoramiento de la calidad más cuestionada que aquella referida a la equidad. Así la nota promedio que los directivos pusieron al gobierno en materia de promoción de la calidad el año 2017 fue de 3,7 puntos (la misma por lo demás que pusieron en los años anteriores), mientras que la nota obtenida para equidad alcanzó 4,3 puntos.

Esta percepción de reformas, percibidas como más orientadas hacia la equidad que hacia la calidad, se expresa con claridad en otras respuestas de los directores. Por ejemplo, en la encuesta del año 2016 los encuestados se manifestaban en un 66\% De acuerdo o Muy de acuerdo con la afirmación de que las reformas impulsadas por el gobierno "han permitido poner en el centro de la discusión la inequidad de la educación escolar en Chile". Al mismo tiempo un $82 \%$ de ellos pensaba que las reformas "consideran poco lo que ocurre en el aula" y un $73 \%$ que ellas "se han centrado más en aspectos institucionales y de gestión que en mejorar la calidad".

Se reitera en esta evaluación específica la diferencia por dependencia. Mientras los directores del sector privado suelen tener opiniones muy críticas del actuar gubernamental, sus colegas del sector público tienden a valorizar más su labor. Así, por ejemplo, en el año 2017, los directivos que trabajan en establecimientos privados subvencionados evaluaron al gobierno con notas de 3,3 en materia de mejoramiento de la calidad y de 4,0 en equidad, y aquellos del sector público lo hicieron con notas de 4,2 y de 4,7 respectivamente. Una clave para entender esta diferencia de opinión según la dependencia dice relación con la percepción existente en el sector privado subvencionado de que las reformas realizadas por el gobierno buscarían perjudicarlos en aras de fortalecer al sector público. Así en el año 2016 el 70\% de los directivos de establecimientos privado subvencionados pensaba que las reformas "han perjudicado a los establecimientos particulares subvencionados" y el 65\% opinaba que "la mayoría (de las reformas) beneficiarán a la educación pública”. En el caso de los directores del sector municipal, estos porcentajes llegaron solamente a un 13 y $39 \%$, respectivamente.

Del mismo modo los datos ratifican la existencia de una baja significativa en la opinión positiva sobre el actuar gubernamental en el primer año de gestión de la administración Bachelet -lo que hemos denominado anteriormente el shock inicial. En efecto, la comparación entre el año 2013 (pre-Bachelet) y 2014 muestra que se pasa de una nota de 4,1 (azul) a una de 3,7 (roja) en cuanto al juicio sobre el desempeño gubernamental en el mejoramiento de la calidad y equidad educativa.

La opinión sobre las políticas gubernamentales se complementa en la encuesta con la evaluación que los directivos realizan de los ministros, que son la cara visible de aquellas y quienes desarrollan su gestión política y comunicacional. El gobierno de Michelle Bachelet contó con dos ministros de educación: Nicolás Eyzaguirre (2014-2015) y Adriana Delpiano (2015-2018). La encuesta preguntó a los directivos su opinión sobre ambos, incluso cuando el primero de ellos ya no estaba en funciones. En el caso de Eyzaguirre, se trata del ministro peor evaluado de toda la serie de ministros seguidos por la encuesta, 
con una nota recurrente de 3,1. La ministra Delpiano cuenta con una mejor evaluación relativa, alcanzando el año 2017 la nota 3,7 (los años anteriores obtuvo 3,6). De manera que la mejor evaluación que van teniendo las políticas gubernamentales en el transcurso del gobierno, evoluciona en paralelo con la mayor aceptación que van teniendo las autoridades sectoriales por parte de los directivos escolares.

\subsection{Las principales políticas y su visión diferenciada por los directivos}

Como se ha señalado, el gobierno de Michelle Bachelet tuvo tres iniciativas legales principales que involucraban a los directivos escolares. Estas leyes se promulgaron en momentos distintos del período gubernamental (inicio, medio y término) y tuvieron distintas apreciaciones por parte de este actor educativo.

\subsubsection{La ley de inclusión}

La ley de inclusión es ampliamente conocida por los directivos: en la encuesta 2017, un $79 \%$ declara conocerla "Muy bien" (mientras que un 21\% declara conocerla "Algo"). La información recogida permite distinguir (y analizar) la opinión directiva desde dos ángulos diferentes: el de la iniciativa legal en general y el del efecto que se prevé que la ley tendrá en el propio establecimiento escolar.

En cuanto a la ley de inclusión en general los directores tienen una opinión matizada, con luces y sombras. Por una parte, mayoritariamente se valora el que esta iniciativa avance en cuanto a una mayor integración social, viéndose positivamente que se tenga un sistema de admisión que no discrimine por razones sociales o académicas y confiándose en que ello redundará en un sistema escolar más equitativo. Pero al mismo tiempo se piensa que los establecimientos no están suficientemente preparados para hacerse cargo educativamente de esta mayor diversidad del estudiantado. Adicionalmente se piensa, por parte de la mayoría de los directivos, que no es evidente que la ley sea un aporte al mejoramiento de la calidad de la enseñanza. En paralelo, y en un cuestionamiento indirecto al lucro, se valora mayoritariamente que la ley asegure que los recursos invertidos en educación sean destinados íntegramente a labores de enseñanza. También se cree que los sectores de menores recursos se verán beneficiados con esta iniciativa educacional. El clivaje ya detectado entre los directivos de las dos dependencias se manifiesta con nitidez en relación con las opiniones que se tienen respecto de esta ley, siendo los del sector público más proclives a apreciar sus aportes para la educación nacional. Un tema específico que levanta la mitad de los directores del sector privado subvencionado es el efecto restrictivo que tendría esta ley en términos de las posibilidades de ejercer la libertad de elección de escuela por parte de las familias -aunque paradojalmente ellos piensan que la puesta en marcha de la ley impactará en que, producto del término del copago, estudiantes que hoy asisten a establecimientos municipales se trasladarán al sector... iprivado subvencionado! El cuadro 5 da cuenta de las matizadas opiniones que los directivos escolares se plantean respecto de la ley de inclusión.

Los directivos también fueron consultados respecto de los efectos que la ley de inclusión tendría directamente en los establecimientos que ellos dirigen. Los resultados muestran que esta iniciativa tuvo una evolución ascendente en la subjetividad directiva durante el período gubernamental, siendo crecientemente aceptada como positiva para el propio colegio. Es así que si el año 2015 solo el 17\% de los directores pensaba que la ley tendría un impacto positivo en el establecimiento, el 2016 ese porcentaje había aumentado al 30\% 
y para el 2017 se empinaba al 43\%. Esta evolución se da en ambas dependencias, pero alcanza distintos puntos de llegada, como puede apreciarse en el gráfico 3.

Cuadro 5. Percepción sobre Ley de inclusión por dependencia (\% Muy De Acuerdo y \%De Acuerdo)

\begin{tabular}{|c|c|c|c|c|}
\hline & ToTAL & MUNICIPAL & $\begin{array}{c}\text { PARTICULAR } \\
\text { SUBVENCIONADO } \\
\end{array}$ & $\begin{array}{c}\text { PARTICULAR } \\
\text { PAGADO } \\
\end{array}$ \\
\hline $\begin{array}{l}\text { Los colegios están poco preparados } \\
\text { para enseñar en un contexto de } \\
\text { mayor diversidad de aprendizajes }\end{array}$ & $74 \%$ & $68 \% *$ & $78 \% *$ & $85 \%$ \\
\hline $\begin{array}{l}\text { La Ley contribuirá a un proceso de } \\
\text { admisión escolar que no discrimine } \\
\text { por el origen social ni por las } \\
\text { capacidades de los estudiantes }\end{array}$ & $68 \%$ & $72 \% *$ & $63 \%$ & $63 \%$ \\
\hline $\begin{array}{l}\text { La Ley permitirá un sistema } \\
\text { educacional más equitativo, diverso } \\
\text { y respetuoso de las diferencias de los } \\
\text { estudiantes }\end{array}$ & $64 \%$ & $75 \% *$ & $53 \%$ & $58 \%$ \\
\hline $\begin{array}{l}\text { La Ley impactará poco o nada la } \\
\text { calidad de la educación en Chile }\end{array}$ & $57 \%$ & $49 \%$ & $68 \% *$ & $53 \%$ \\
\hline $\begin{array}{l}\text { El fin al lucro ayudará a que todos los } \\
\text { recursos se usen en beneficio de los } \\
\text { aprendizajes de los estudiantes }\end{array}$ & $52 \%$ & $51 \%$ & $55 \%$ & $30 \% *$ \\
\hline $\begin{array}{l}\text { Las familias de menos recursos se } \\
\text { verán beneficiadas por la Ley }\end{array}$ & $52 \%$ & $53 \%$ & $51 \%$ & $45 \%$ \\
\hline $\begin{array}{l}\text { Dado que la Ley termina con el } \\
\text { copago, muchos alumnos y familias } \\
\text { se irán del sector municipal al sector } \\
\text { particular subvencionado }\end{array}$ & $47 \%$ & $42 \% *$ & $52 \%$ & $53 \%$ \\
\hline $\begin{array}{l}\text { El nuevo sistema de admisión } \\
\text { reducirá la libertad de las familias de } \\
\text { elegir un colegio para sus hijos }\end{array}$ & $38 \%$ & $28 \%$ & $50 \% *$ & $35 \%$ \\
\hline
\end{tabular}

Nota: Base Encuesta 2016. Total de Directores. $\mathrm{N}=575$. *Las diferencias entre los porcentajes correspondientes a cada dependencia administrativa, respecto de las otras dos categorías, son estadísticamente significativas con un 95\% de confianza.

Fuente: Elaboración propia.

$\mathrm{Al}$ indagarse en los aspectos que les resultan más y menos fáciles de gestionar de la ley, los directivos piensan que lo más problemático consiste en la adecuada administración de la mayor diversidad estudiantil dentro del establecimiento -en especial se plantea mayoritariamente que el colegio no está suficientemente preparado para "enseñar en contextos de mayor diversidad de aprendizajes", así como para "mantener en el establecimiento a alumnos con problemas de disciplina”. En contrapartida se piensa mayoritariamente que sí se tienen las capacidades suficientes para administrar adecuadamente los recursos adicionales que conlleva la ley y para trabajar con alumnos con menor rendimiento académico. Llama la atención de que, a diferencia del juicio general sobre la ley, no existen mayores diferencias por dependencia cuando se opina sobre estos aspectos a gestionar en el propio establecimiento que conlleva la ley de inclusión, siendo las dificultades similares para los distintos directivos. 


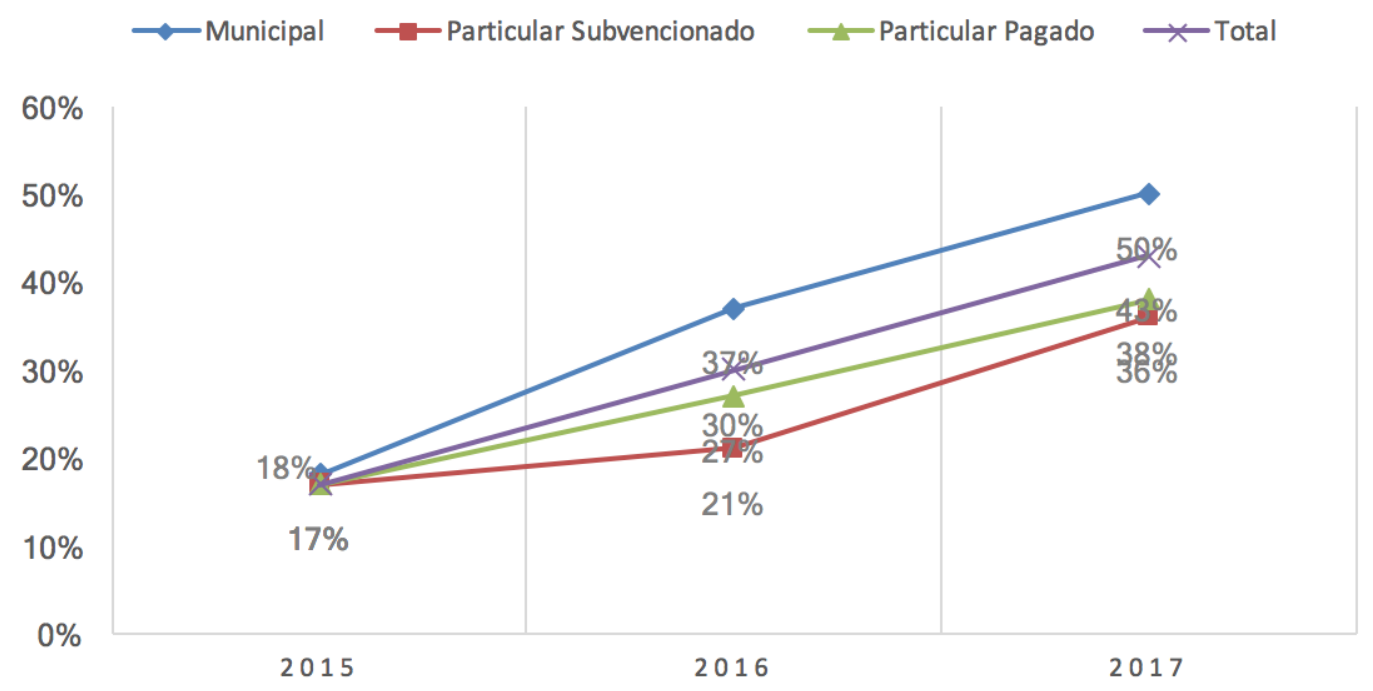

Gráfico 3. En relación específicamente con el establecimiento que dirige, Ud. cree que la nueva ley de inclusión: (\% impactará positivamente el funcionamiento del establecimiento)

Fuente: Encuesta "La Voz de los Directores".

\subsubsection{La ley de carrera profesional docente}

La ley que crea una nueva carrera profesional para los docentes era mayoritariamente conocida en el año final del gobierno de Bachelet: $69 \%$ de los directores decía conocerla muy bien (versus $30 \%$ que la conocía algo). Es notorio que el conocimiento es menor entre los directivos del sector privado pagado (solo $26 \%$ dice conocerla muy bien), en que efectivamente esta ley tiene una mucha menor incidencia -puesto que seguirán manteniendo sus mismas condiciones laborales.

$\mathrm{Al}$ consultar respecto de aspectos generales de la ley se aprecia que ella recibe una opinión más bien favorable de parte de los directivos escolares, aunque no se piense que ella resuelva todos los desafíos de la "cuestión docente". Así se valora unánimemente el aumento del tiempo no-lectivo en el contrato de trabajo de los docentes, que les permite tener una mayor proporción de su jornada laboral para la preparación de la enseñanza y su desarrollo profesional. También se cree mayoritariamente que el acompañamiento, mediante mentorías e inducción, permitirá un mejor desarrollo (y desempeño) profesional de los docentes.

La relevancia y aceptación general de esta ley se expresa también de una manera indirecta: se desearía muy mayoritariamente contar con una ley equivalente pero enfocada ya no en los docentes sino que en ellos mismos, vale decir una carrera profesional para los directivos escolares ${ }^{4}$. En cambio los puntos sobre los cuáles no hay plena convicción de que la ley cumpla totalmente sus propósitos parecen ser dos: la transformación de la formación inicial de los docentes (no creyéndose que baste la acreditación ni la admisión de alumnos con mejor puntaje de ingreso para mejorar la acción formativa de las facultades

\footnotetext{
${ }^{4}$ El hecho de que la ley se enfocara exclusivamente en los docentes de aula y no en los directivos tuvo el efecto colateral de que muchos directivos, en particular en el sector público, se vieran equiparados o superados en sus remuneraciones por algunos docentes.
} 
de educación) y el cambio del prestigio social de la profesión docente (no confiándose en que los nuevos salarios incluidos en la carrera sean lo suficientemente poderosos como para cambiar la situación de desmedro existente en la sociedad). Adicionalmente existe una opinión dividida respecto del efecto que tendrá esta nueva carrera en el mejoramiento de la calidad de la enseñanza. En la apreciación general de esta ley, a diferencia de la ley de inclusión, no se produce una división de opiniones tan sistemática y tajante entre los directivos que trabajan en el sector público y en el sector privado subvencionado. Hay ámbitos en que ambos grupos tienen percepciones muy similares e incluso hay veces en que la valoración del sector privado subvencionado de esta iniciativa gubernamental es superior al de los directivos públicos. La diferencia mayor, en este plano, parece producirse respecto de los directivos que trabajan en el sector privado pagado, entre quienes se tiende a cuestionar más la nueva ley y a poner en entredicho sus eventuales efectos. Las opiniones de los directivos sobre esta ley pueden apreciarse en detalle en el cuadro 6.

Cuadro 6. Percepción sobre la ley de carrera docente por dependencia (\% Muy de Acuerdo y De acuerdo)

\begin{tabular}{|c|c|c|c|c|}
\hline & Total & MUNICIPAL & $\begin{array}{c}\text { PRIVADO } \\
\text { SUBVENCIONADO }\end{array}$ & $\begin{array}{c}\text { PRIVADO } \\
\text { PAGADO }\end{array}$ \\
\hline $\begin{array}{l}\text { Un aspecto positivo de la nueva Ley } \\
\text { es la disminución de las horas } \\
\text { lectivas de los docentes }\end{array}$ & $86 \%$ & $88 \%$ & $85 \%$ & $82 \%$ \\
\hline $\begin{array}{l}\text { En el país debiéramos contar con una } \\
\text { ley equivalente, pero enfocada en la } \\
\text { carrera directiva }\end{array}$ & $78 \%$ & $81 \%$ & $75 \%$ & $67 \%$ \\
\hline $\begin{array}{l}\text { La acreditación obligatoria de todas } \\
\text { las carreras de pedagogía es una } \\
\text { medida insuficiente para elevar la } \\
\text { calidad de los programas de } \\
\text { formación inicial docente }\end{array}$ & $70 \%$ & $67 \%$ & $75 \% *$ & $64 \%$ \\
\hline $\begin{array}{l}\text { Los procesos de acompañamiento a } \\
\text { docentes que establece la Ley, a } \\
\text { través de mentorías e inducción, } \\
\text { son fundamentales para un mejor } \\
\text { desempeño docente }\end{array}$ & $63 \%$ & $58 \% *$ & $67 \% *$ & $79 \%$ \\
\hline $\begin{array}{l}\text { Los mayores puntajes y exigencias de } \\
\text { acceso a las carreras de pedagogía, } \\
\text { elevará la calidad de los futuros } \\
\text { docentes }\end{array}$ & $52 \%$ & $52 \%$ & $51 \%$ & $61 \% *$ \\
\hline $\begin{array}{l}\text { La nueva carrera docente remunera } \\
\text { inadecuadamente el buen } \\
\text { desempeño de los profesores }\end{array}$ & $51 \%$ & $50 \%$ & $54 \%$ & $30 \% *$ \\
\hline $\begin{array}{l}\text { La implementación de la nueva Ley } \\
\text { Docente tendrá un impacto mínimo } \\
\text { o nulo sobre la calidad de los } \\
\text { aprendizajes }\end{array}$ & $47 \%$ & $45 \%$ & $52 \%$ & $36 \% *$ \\
\hline $\begin{array}{l}\text { La nueva Ley dignifica la profesión } \\
\text { docente y contribuirá a una mayor } \\
\text { valoración social de los profesores }\end{array}$ & $37 \%$ & $36 \%$ & $37 \%$ & $42 \%$ \\
\hline
\end{tabular}

Nota: Base Encuesta 2016. Total de Directores. $\mathrm{N}=575$. *Las diferencias entre los porcentajes correspondientes a cada dependencia administrativa, respecto de las otras dos categorías, son estadísticamente significativas con un $95 \%$ de confianza.

Fuente: Elaboración propia. 
¿Qué efectos se cree que tendrá la nueva ley de carrera docente en el propio establecimiento? La mayoría de los directores $(53 \%)$ piensa que ella tendrá un impacto positivo, mientras que un grupo relevante $(38 \%)$ cree que no tendrá un efecto ni positivo ni negativo, y un grupo muy menor $(9 \%)$ piensa que tendrá un impacto negativo. Debe señalarse que, al igual que en el caso de la ley de inclusión, el grupo que augura un efecto positivo ha crecido del año 2016 al 2017, y en nada menos que 20 puntos (de un tercio a la mitad de los directivos), como puede apreciarse en el gráfico 4.

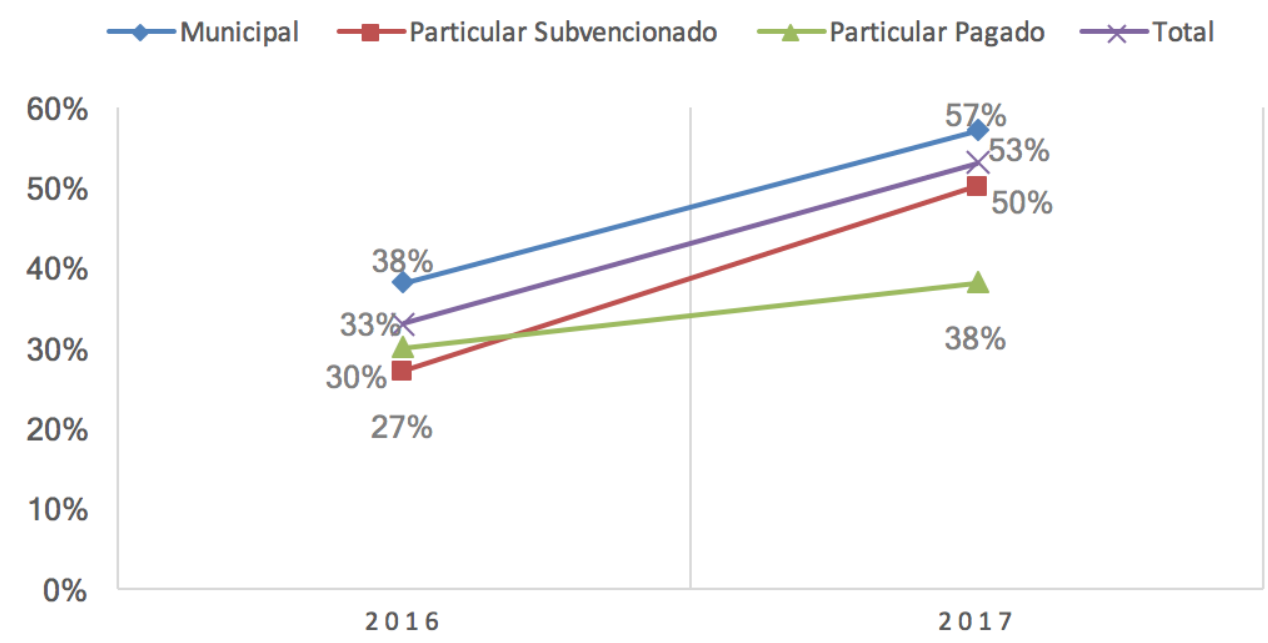

Gráfico 4. En relación específicamente con el establecimiento que dirige, Ud. cree que la nueva ley de carrera docente: (\% impactará positivamente el funcionamiento del establecimiento)

Fuente: Encuesta "La Voz de los Directores".

Adicionalmente, se consultó a los directores respecto de los aspectos en que se sentían más y menos preparados para implementar esta nueva iniciativa legal en sus propios establecimientos. La respuesta indica que "guiar y conducir el uso de las horas no lectivas" aparece como el ámbito en que se sienten más preparados (el $75 \%$ se considera Bien o Altamente preparado), mientras que se sienten con una menor capacidad respecto de "implementar la inducción de docentes nuevos" (51\%), "atraer y contratar nuevos docentes debido al aumento de las horas no lectivas" (51\%), y "diseñar planes de desarrollo profesional docente adecuados a las necesidades de los docentes" (50\%). Las diferencias de opinión por dependencia se comportan de manera similar al enjuiciamiento general de la ley de nueva carrera: escasa diferencia entre directivos de sector público y privado subvencionado, pero mayor distancia de ambos, en ciertos ítemes, con quiénes lideran establecimientos privados pagados.

\subsubsection{La ley de nueva educación pública}

Se realizaron algunas consultas generales sobre la ley de fortalecimiento de la educación pública (o de “desmunicipalización”), la que, como se recordará, solo viene a aprobarse hacia el final del período bacheletista y repercutirá lentamente -debido a su gradualidad de 8 años- sobre la totalidad de establecimientos públicos. En cuanto al conocimiento, se constató que esta ley era ampliamente desconocida para los directores: solo un 25\% decía conocerla bien, mientras que la mayoría (63\%) decía conocerla algo y un grupo reducido $(10 \%)$ declaraba no conocerla para nada. 
El conocimiento declarado aumenta en el grupo directamente implicado, los directores de establecimientos públicos, pero aún entre ellos se trata de una minoría (35\%) quienes dicen conocerla muy bien. Respecto del impacto esperado en el propio establecimiento, la opinión mayoritaria es que no tendrá mayor impacto. Entre los directivos directamente implicados, aquellos del sector público, hay un grupo considerable (43\%) que sí cree que la ley tendrá un efecto positivo, pero al mismo tiempo existe un grupo equivalente (41\%) que opina que no tendrá mayor impacto -a lo que se agrega un grupo minoritario (16\%) que cree que tendrá un efecto negativo. De modo que pareciera que esta última ley, a diferencia de las dos anteriores, no se constituyó para los directivos en un eje de opinión significativo sobre las políticas educativas del gobierno de Michelle Bachelet.

\subsection{Las prioridades para la política educativa}

Hacia el final del período, la priorización de las medidas que los directores consideran necesarias de tomar para la educación en Chile tiene en sus dos primeros lugares el mejoramiento de la formación inicial de los futuros docentes y la entrega de mayor autonomía a los establecimientos para la gestión de recursos. Esta demanda por mayor autonomía es levantada más fuertemente por quienes se desempeñan en establecimientos públicos, que efectivamente poseen menores atribuciones en materia de gestión de recursos humanos y materiales (Weinstein y Muñoz, 2009).

El resto de las medidas, priorizadas por grupos más reducidos de directivos, también sigue este patrón de una relativa diferenciación por dependencia: mientras en el sector privado se da mayor importancia a la formación continua de los docentes y al cambio del currículo y los planes de estudio, en el público se reivindica la importancia de medidas más estructurales como la de desmunicipalizar la educación pública o de modificar el sistema de financiamiento de las escuelas (basado actualmente en la subvención por alumno asistente al colegio).

Llama la atención que no se plantee como prioridad el contar con mayor financiamiento en general, ni el contar con más recursos educativos o tampoco la medida de garantizar el acceso y la calidad de la educación preescolar, que suele ser mencionada como una de las principales por parte de actores políticos y académicos del sector educación. El cuadro 7 da cuenta de las medidas consideradas prioritarias por los directores.

Un resultado importante que arroja la comparación longitudinal de las encuestas en el período 2014-2017, refiere al cambio de la percepción de medidas prioritarias respecto de la docencia de aula. En efecto, el sitial ocupado por la necesidad de transformar la formación inicial docente se mantiene inalterable como la medida predilecta de los directores durante los cuatro años. Hay, en cambio, un cambio significativo en la urgencia e importancia otorgada por los directores a mejorar las condiciones de trabajo de los docentes: si el año 2015 el 52\% de los directores ubicaba a esta medida entre las prioritarias, ese porcentaje baja a un $25 \%$ para el año 2017. Igualmente se produce una tendencia a disminuir la prioridad otorgada a mejorar la formación continua de los docentes (se pasa del 44\% al 24\% entre los dos años referidos). En este sentido es que la ley de nueva carrera docente parece haber impactado indirectamente la opinión de los directivos, alterando sus prioridades de políticas. Debe anotarse, adicionalmente, que en la situación previa a la nueva carrera había una menor dispersión de opiniones entre los directivos escolares, estando ellas concentradas justamente en las temáticas docentes que la ley vino a enfrentar. 
Cuadro 7. Priorización de medidas para mejorar educación según dependencia (3 más importantes)

\begin{tabular}{lcccc}
\hline & TOTAL & MUNICIPAL & $\begin{array}{c}\text { PART. } \\
\text { SUB }\end{array}$ & $\begin{array}{c}\text { PART. } \\
\text { PAG }\end{array}$ \\
\hline $\begin{array}{l}\text { Mejorar la formación inicial docente } \\
\text { Entregar más autonomía a los establecimientos }\end{array}$ & $47 \%$ & $45 \%$ & $46 \%$ & $79 \% *$ \\
$\quad$ educacionales para la gestión de recursos & $45 \%$ & $51 \% *$ & $38 \% *$ & $32 \% *$ \\
$\quad \begin{array}{l}\text { Modificar el sistema de subvenciones por asistencia } \\
\text { Desmunicipalizar la educación pública }\end{array}$ & $32 \%$ & $37 \% *$ & $28 \%$ & $6 \% *$ \\
$\quad \begin{array}{l}\text { Mejorar las condiciones de trabajo de los docentes, } \\
\text { premiando su desempeño }\end{array}$ & $26 \%$ & $37 \% *$ & $13 \% *$ & $15 \% *$ \\
$\begin{array}{l}\text { Mejorar la formación continua para docentes } \\
\text { Mejorar el currículum y los planes de estudio }\end{array}$ & $24 \%$ & $24 \%$ & $27 \%$ & $26 \%$ \\
Fortalecer el apoyo técnico para los & $24 \%$ & $20 \%$ & $29 \% *$ & $29 \% *$ \\
$\quad$ establecimientos & $22 \%$ & $22 \%$ & $24 \%$ & $6 \% *$ \\
$\quad \begin{array}{l}\text { Mejorar la formación de los directivos } \\
\text { Aumentar la subvención escolar }\end{array}$ & $19 \%$ & $15 \%$ & $22 \%$ & $29 \% *$ \\
Garantizar el acceso y calidad de la educación & $16 \%$ & $14 \%$ & $20 \%$ & $12 \%$ \\
$\quad$ preescolar & $9 \%$ & $7 \%$ & $8 \%$ & $24 \% *$ \\
Entregar más recursos de aprendizaje & $4 \%$ & $3 \%$ & $6 \%$ & $3 \%$ \\
\hline
\end{tabular}

Nota: Base Encuesta 2017. Total de Directores. N=627. *Las diferencias entre los porcentajes correspondientes a cada dependencia administrativa, respecto de las otras dos categorías, son estadísticamente significativas con un 95\% de confianza.

Fuente: Elaboración propia.

\section{Discusión y conclusiones}

Los resultados de la encuesta "La voz de los directores" durante los cuatro años del gobierno de Michelle Bachelet, con la posibilidad adicional de comparación con el año previo a su inicio (2013), brindan una base única de información sobre cómo este relevante actor educativo se posicionó frente a las políticas educativas puestas en marcha en el período. Una buena implementación de las reformas (cuyo éxito e impacto educativo se jugará precisamente en los próximos años) supone comprender adecuadamente cómo los directivos están percibiendo e interpretando estas políticas (O’Laughlin y Lindle, 2015).

De acuerdo a la evidencia que proporciona la encuesta, resulta notorio que la iniciativa principal que marcó la gestión gubernamental de la presidenta Bachelet fue la ley de inclusión, por sobre la ley de carrera docente y más por sobre todavía de la ley de nueva educación pública, que se aprobó recién a fines del período y no alcanzó a constituirse como un referente de opinión.

Más allá de la temporalidad con la que se fueron discutiendo y aprobando estas leyes, es claro que fue precisamente en torno a la ley de inclusión, con su dura discusión pública durante su tramitación legislativa y su posterior promulgación (Muñoz y Weinstein, en prensa), que se producen dos procesos claves en cuanto a la opinión directiva. Por una parte, se genera, respecto del momento previo a la asunción del gobierno bacheletista, una visión más negativa de la situación de la educación chilena, la que va unida a un mayor pesimismo sobre su situación futura. Muchos directores pusieron en duda el real aporte de esta ley al mejoramiento de la calidad educativa y pensaron que ella podría tener efectos incluso negativos respecto de su desarrollo. Se produjo así una brecha, muy compleja para la implementación, entre la política propuesta a nivel macro y las creencias y motivaciones 
a nivel de las escuelas (Cuenca y Cáceda, 2017; Fullan, 1985; Rigby, Woulfin y März, 2016).

Por otra parte, esta ley generó una mayor diferenciación en la opinión de los directivos, distanciándose la opinión de aquellos que trabajaban en establecimientos municipales respecto de quienes lo hacían en establecimientos privados. Recordemos que para los primeros el efecto de esta ley fue más bien acotado (aumento de recursos) y no implicó un cambio sustantivo en sus "reglas del juego". No ocurrió lo mismo para quienes lideraban establecimientos privados subvencionados, en que la ley si alteraba los modos de trabajar y de relacionarse con los estudiantes y las familias. La ley implicaba, para ellos, una mayor incertidumbre. Además debe considerarse que los directores de los establecimientos privados tienen una relación de mayor cercanía y confianza con sus sostenedores que la que poseen sus colegas del sector municipal (Weinstein et al, 2016), lo que facilitó su comunión de opiniones y su solidaridad frente a situaciones en que los segundos se sintieron amenazados.

La cobertura temporal de los datos recolectados da cuenta de la visión general de la educación con que los directivos iniciaron y terminaron el período bacheletista. En este sentido, la apreciación general de la educación chilena como mediocre no sufrió cambios sustanciales con la acción de un gobierno que fue más valorado por su acción en materia de equidad que de calidad. Lo que sí se modifica, aunque parcialmente, son las medidas que se piensa que pueden impactar en mejorar la calidad de la educación nacional y que debieran de ser, a ojos de los directivos, prioridad para los gobiernos. En este sentido, si bien se mantiene la formación inicial de los docentes como prioridad uno, disminuye la importancia otorgada a mejorar las condiciones de trabajo de los docentes, así como aquella entregada a aumentar la calidad de la formación continua. Pareciera que la aceptación que los directivos otorgaron a la ley de nueva carrera profesional para los docentes tuvo el efecto de desplazar el nivel de urgencia dado previamente a estas dimensiones, que justamente constituyen el meollo de dicha iniciativa legal.

Los resultados de la encuesta muestran que la opinión de los directivos fue variando durante el cuatrienio de gobierno, lo que es notorio en su optimismo/pesimismo respecto del futuro educativo del país -pero también, en paralelo, es verificable en su opinión sobre el efecto de la ley de inclusión en el establecimiento escolar que dirigen. El movimiento de opinión estuvo marcado por un shock inicial el año 2014, en que se desplomó la visión del futuro educativo y cundió el pesimismo en muchos directores, para luego irse gradualmente recuperando la confianza. ¿Qué puede explicar esta recuperación del optimismo? Nuestra hipótesis es que se combinan al menos tres factores. Primero, que a medida que la ley de inclusión se fue implementando se va despejando la incertidumbre (por ejemplo, no se cumplió con la visión de un masivo cierre de colegios privados subvencionados que habían anunciado los voceros de los sostenedores de este sector) y, por el contrario, muestra algunos elementos valiosos para los establecimientos, como la llegada de nuevos recursos (Muñoz y Weinstein, en prensa). Segundo, se tramita y luego aprueba la ley de carrera docente, la que, a pesar de la movilización y paro docente, sí tiene buena aceptación de parte de los directivos, quiénes, recordémoslo, consideraban transversalmente que mejorar las condiciones de trabajo de los docentes era una de las prioridades a atender en el sector. Con ello, además, la ley de inclusión deja de ser la única iniciativa gubernamental presente. Por último, parece haber mejorado la gestión política y comunicacional del gobierno, lo que se aprecia en la mejor evaluación directiva que se 
tiene de la ministra Delpiano respecto del ministro Eyzaguirre. Cada uno de estos factores contribuyó a acortar la brecha creada en el primer año.

De manera más general, los resultados de las encuestas realizadas evidencian que los directores escolares son "informantes cualificados" de las políticas gubernamentales. Es así como poseen una opinión matizada, que es capaz de apreciar diferentes aspectos que plantean las nuevas políticas, observándolas y evaluándolas en su complejidad. Su escepticismo respecto de que la nueva carrera docente, que es una política que goza de su valoración general, logre modificar la formación inicial de los docentes que otorgan las universidades o bien logre transformar el bajo prestigio social que posee la profesión docente en la sociedad chilena actual, es un botón de muestra al respecto. Pero adicionalmente los directivos brindan una información única y estratégica: dan cuenta de las dificultades con que se encuentran (o encontrarán a futuro) las políticas al momento de ser implementadas en la realidad escolar misma. Es así como, por ejemplo, los directivos consideran que la ley de inclusión será especialmente difícil de poner en marcha por la falta de preparación con que se cuenta en sus centros para enseñar con una mayor diversidad de estudiantes, al mismo tiempo que consideran que la nueva carrera docente se verá en aprietos para poner en marcha el inédito sistema de mentorías para los docentes nóveles. Por ello, la "voz de los directores" debiera ser estudiada, conocida y ponderada por los tomadores de decisión al momento de diseñar e implementar las políticas educativas, cuya materialización y traducción en mejores oportunidades de aprendizaje en las aulas requiere finalmente del concurso activo de los líderes escolares (Rivas, 2015; Vázquez, Bernal Agudo y Liesa, 2014; Young y Lewis, 2015). Levantar esta estratégica información, y hacerla circular oportunamente en el espacio público, constituye una poderosa herramienta con que los investigadores en liderazgo y mejoramiento escolar de América Latina podrían aumentar su incidencia en la calidad educativa.

\section{Agradecimientos}

El estudio que dio origen al artículo contó con el apoyo de CEDLE (Centro de Desarrollo del Liderazgo Educativo).

\section{Referencias}

Barber, M. y Mourshed, M. (2007). How the world's best education systems come out on top. Londres: McKinsey.

Bellei, C., Cabalín, C. y Orellana, V. (2014). The 2011 Chilean movement against neoliberal educational policies. Studies in Higher Education, 39(3), 426-440. https://doi.org/10.1080/03075079.2014.896179

Bellei, C. (2015). El gran experimento: Mercado y privatización de la educación chilena. Santiago de Chile: LOM ediciones.

Cabalín, C. y Antezana, L. (2016). La educación en portada: La visualización de la política educacional en la prensa. Cuadernos Info, 39, 195-207. https://doi.org/10.7764/cdi.39.914

CEP. (2015). Encuesta de opinión pública. Santiago de Chile: Centro de Estudios Públicos.

Cox, C. (2012). Política y políticas educacionales en Chile 1990-2010. Revista Uruguaya de Ciencia Política, 21(1), 13-43. 
Cuenca, R. y Cáceda, J. (2017). Ideales normativos, normas y praxis: Patologías sobre los directivos escolares en el Perú. REICE. Revista Iberoamericana sobre Calidad, Eficacia y Cambio en Educación, 15(2), 5-29. https://doi.org/10.15366/reice2017.15.2.001

Day, C., Gu, Q. y Sammons, P. (2016). The impact of leadership on student outcomes: How successful school leaders use transformational and instructional strategies to make a difference. Educational Administration Quarterly, 52(2), 221-258. https://doi.org/10.1177/0013161X15616863

Elmore, R. y McLaughlin, M. W. (1982). Strategic choice in federal education policy: The compliance-assistance tradeoff. En A. Lieberman y M. W. McLaughlin (Eds.), Policymaking in education, 81 st yearbook of the national society for the study of education (pp. 159-194). Chicago: University of Chicago Press.

Fixsen, D. L., Naoom, S. F., Blase, K. A. y Friedman, R. M. (2005). Implementation research: A synthesis of the literature. Tampa, FL: University of South Florida.

Fullan, M. (1985). Change processes and strategies at the local level. The Elementary School Journal, 85(3), 391-421. https://doi.org/10.1086/461411

Fullan, M. (2002). The change. Educational Leadership, 59(8), 16-20.

Fullan, M. (2007). The new meaning of educational change. Nueva York, NY: Teachers College Press.

Fullan, M. (2017). Liderar los aprendizajes: Acciones concretas en pos de la mejora escolar. En J. Weinstein y G. Muñoz (Ed.), Mejoramiento y liderazgo en la escuela. Once miradas (pp. 34-55). Santiago de Chile: Ediciones Universidad Diego Portales.

Hargreaves, A. y Fullan, M. (2012). Professional capital: Transforming teaching in every school. Nueva York, NY: Teachers College Press.

Leithwood, K., Harris, A. y Hopkins, D. (2008). Seven strong claims about successful school leadership. School Leadership and Management, 28(1), 27-42. https://doi.org/10.1080/13632430701800060

MINEDUC. (2017). Estadísticas de la educación 2016. Santiago de Chile: MINEDUC

Muñoz, G. (2013). Claves de una nueva reforma educacional para el Chile que viene. Santiago de Chile: Editorial Ariel.

Muñoz, G. y Weinstein, J. (en prensa). Ley de inclusión: El difícil proceso para redefinir las reglas del juego de la educación particular subvencionada en Chile.

OECD. (2017). Revisión de políticas nacionales en educación: Chile. París: OECD.

O’Laughlin, L. y Lindle, J. C. (2015). Principals as political agents in the implementation of IDEA's least restrictive environment mandate. Educational Policy, 29(1), 140-161. https://doi.org/10.1177/0895904814563207

Rigby, J. G., Woulfin, S. L. y März, V. (2016). Understanding how structure and agency influence education policy implementation and organizational change. American Journal of Education, 122(3), 295-302. https://doi.org/10.1086/685849

Rivas, A. (2015). América Latina después de PISA. Lecciones aprendidas de la educación en siete países. Buenos Aires: CIPPEC.

Seashore-Louis, K., Dretzke, B. y Wahlstrom, K. (2010). How does leadership affect student achievement? Results from a national US survey. School Effectiveness and School Improvement, 21(3), 315-336. https://doi.org/10.1080/09243453.2010.486586

Serrano, S. (2012). Historia de la educación en Chile (1810-2010): Aprender a leer y escribir (1810-1880). Santiago de Chile: Taurus. 
Stein, M., Grover, B. y Henningsen, M. (1996). Building student capacity for mathematical thinking and reasoning: An analysis of mathematical tasks used in reform classrooms. American Educational Research Journal, 33(2), 455-488. https://doi.org/10.3102/00028312033002455

Sun, M., Kenneth,F., Penuel, W. y Chong Min, K. (2013). How external institutions penetrate schools through formal and informal leaders. Educational Administration Quarterly, 49(4), 610-644. https://doi.org/10.1177/0013161X12468148

UNICEF. (2014). La voz del movimiento estudiantil 2011. Educación pública, gratuita y de calidad. Algunas lecciones para el sistema educativo chileno. Santiago de Chile: UNICEF.

Vázquez, S., Bernal Agudo, J. L. y Liesa, M. (2014). La conceptualización del liderazgo: una aproximación desde la práctica educativa. REICE. Revista Iberoamericana sobre Calidad, Eficacia y Cambio en Educación, 12(5), 79-97.

Weinstein, J. y Muñoz, G. (2009). Calidad para todos. La reforma educacional en el punto de quiebre. En J. Weinstein (Coord.), Más acá de los sueños, más allá de lo posible: La concertación en Chile (pp. 77-93). Santiago de Chile: LOM.

Young, T. y Lewis, W. D. (2015). Educational policy implementation revisited. Educational Policy, 29(1), 3-17. https://doi.org/10.1177/0895904815568936

\section{Breve CV de los autores}

\section{José Weinstein}

Sociólogo de la Universidad de Chile y Doctorado en Sociología de la Universidad Católica de Lovaina (Bélgica). Actualmente es Profesor Titular de la Universidad Diego Portales y dirige el Centro de Desarrollo del Liderazgo Educativo. Ejerció como Subsecretario de Educación y Ministro de Cultura en el Gobierno del Presidente Ricardo Lagos (20002006). Ha trabajado en diferentes instituciones nacionales vinculadas a la educación. También ha trabajado como consultor en instituciones internacionales como OECD, UNESCO, CEPAL y otras. Entre el 2012 y el 2015 fue miembro del Consejo Nacional de Educación. Cuenta con más de 60 publicaciones en libros y revistas en las temáticas de educación, juventud, cultura y pobreza. En la actualidad trabaja en temas de liderazgo educativo, mejora escolar y políticas docentes. ORCID ID: https://orcid.org/0000-00024193-4550. Email: jose.weinstein@gmail.com

\section{Gonzalo Muñoz}

Sociólogo y Magíster en Sociología de la Universidad Católica de Chile. Académico de la Facultad de Educación y director del Magíster en Liderazgo y Gestión Educativa de la Universidad Diego Portales. Más de 15 de años de experiencia en educación en Chile y América Latina. Fue jefe de la División de Educación General del Ministerio de Educación de Chile entre los años 2014 y 2016. Trabajó anteriormente como Director de Estudios del Centro de Innovación en Educación de Fundación Chile, Jefe de Estudios de la División de Educación General del Ministerio de Educación e Investigador Asociado de Asesorías para el Desarrollo. En octubre del 2012 fue nombrado consejero de la Agencia de Calidad de la Educación, a través del sistema de Alta Dirección Pública. Ha sido consultor en proyectos del BID, OECD y UNESCO, y ha colaborado con los Ministerios de Educación de Paraguay, Panamá y Honduras. Ha publicado varios libros y artículos en sus áreas de especialidad: políticas educacionales, efectividad y mejoramiento escolar, y 
liderazgo educativo. ORCID ID: https://orcid.org/0000-0001-7219-0841. Email: gonzalo.munozs@mail.udp.cl

\section{Rosario Rivero}

Profesora de la Facultad de Educación Universidad Diego Portales, Santiago, Chile. Licenciada en Economía (Pontifica Universidad Católica de Chile). Magíster en Economía con mención en Políticas Públicas (Pontificia Universidad Católica de Chile) y Doctora en Educación (Universidad de California, Berkeley). En la actualidad realiza docencia a nivel de pregrado en Pedagogía en Educación General Básica y postgrado en el Doctorado en Educación. Participa como investigador asociado al Centro de Liderazgo Educativo (CEDLE). Sus principales líneas de investigación son formación inicial docente, trayectorias laborales, evaluación docente, liderazgo escolar, política educativa y evaluación de programas. ORCID ID: https://orcid.org/0000-0002-6666-9642. Email: rosario.rivero@udp.cl. 